\title{
O uso da própolis como agente cicatrizante e hepatoprotetor
}

The use of propolis as a healer and hepatoprotective agent

\author{
Luiz Henrique Hoffmann ${ }^{1 *} \bullet$, Maykon Jhuly Martins de Paiva ${ }^{2} \bullet$
}

Faculdade de Palmas, Palmas, Tocantins, Brasil. *Autor para correspondência. E-mail: luizhh0@gmail.com

\begin{abstract}
Resumo: Introdução: A própolis vem sido empregada desde sua descoberta como agente anti-inflamatório entre outras finalidades, tendo em vista seus efeitos benéficos, surgiu com a evolução à necessidade de iniciar novos estudos, pesquisadores descobriram, mais de 300 compostos, que na sua maioria são em formas de polifenóis, antioxidantes que combatem doenças e danos no organismo. A própolis é derivada de diferentes partes da planta, como brotos, botões de flores e exsudatos resinosos. Este trabalho tem como objetivos compreender os principais benefícios do uso da própolis como cicatrizante e hepatoprotetor. Para o desenvolvimento deste, os artigos foram selecionados a partir de uma leitura prévia dos resumos com a finalidade de comparar os respectivos pontos propostos, utilizados e discutidos por autor. Revisão: de acordo com os dados literários a aplicação de própolis aumenta a taxa de cicatrização de feridas e a reepitelização de feridas diabéticas em roedores. Em pesquisa mostrara que, com uma única própolis tópica, há um aumento da cicatrização de feridas em um modelo de roedor diabético de cicatrização cutânea de espessura total. Sobre o uso da própolis como hepatoprotetor afirmam que, como o fígado é o principal órgão do metabolismo de compostos, muitas doenças hepáticas aparecem por sua exposição a substâncias tóxicas, e o estresse oxidativo promovido por essas substâncias é muito importante nos mecanismos fisiopatológicos dessas doenças. Discussão: A própolis apresenta resultados positivos como cicatrizante por reduzir a resposta inflamatória, entretanto, seu poder hepatoprotetor é baixo, devido sua administração ser feita por via oral. Considerações finais: Pode afirmar que a própolis possui bons resultados para testes como cicatrizante e hepatoprotetor, mas devem ser desenvolvidos novos ensaios para avaliação dos seus efeitos, bem como formas farmacêuticas e vias de administração para um melhor resultado farmacológico.
\end{abstract}

Palavras-chave: própolis, cicatrizante, hepatoprotetor, extrato, pólen.

\begin{abstract}
Introduction: Propolis has been used since its discovery as an anti-inflammatory agent, among other purposes, in view of its beneficial effects, it emerged with the evolution of the need to initiate new studies, researchers discovered, more than 300 compounds, which in its most are in forms of polyphenols, antioxidants that fight disease and damage to the body. Propolis is derived from different parts of the plant, such as buds, flower buds and resinous exudates. This work aims to understand the main benefits of using propolis as a healing and hepatoprotective agent. For the development of this, the articles were selected from a previous reading of the abstracts in order to compare the respective points proposed, used and discussed by the author. Review: According to the literature, the application of propolis increases the rate of wound healing and re-epithelialization of diabetic wounds in rodents. Research has shown that, with a single topical propolis, there is increased wound healing in a diabetic rodent model of full-thickness skin healing. Regarding the use of propolis as a hepatoprotector, they state that, as the liver is the main organ for the metabolism of compounds, many liver diseases appear due to its exposure to toxic substances, and the oxidative stress promoted by these substances is very important in the pathophysiological mechanisms of these diseases. Discussion: Propolis has positive results as a healing agent by reducing the inflammatory response, however, its hepatoprotective power is low, due to its oral administration. Final Considerations: You can say that propolis has good results for tests as healing and hepatoprotective, but new tests must be developed to evaluate its effects, as well as pharmaceutical forms and administration routes for a better pharmacological result.
\end{abstract}

Keywords: propolis, healing, hepatoprotective, extract, pollen.

\section{Introdução}

A própolis é uma mistura resinosa que as abelhas coletam dos brotos das árvores, dos fluxos de seiva ou de outras fontes botânicas. A composição química da própolis varia e depende da área geográfica, tempo de coleta, sazonalidade, iluminação, altitude e disponibilidade de alimentos durante a exploração da própolis (Oryan et al., 2018). Dependendo de sua cor, odor e consistência, as características da própolis estão 
associadas à sua região de origem, fonte botânica e composição química. Assim, a própolis pode variar de verde, vermelho a marrom, preto e amarelo (Silva et al., 2019).

A própolis é normalmente utilizada na colméia para revestir as paredes internas, para proteger a entrada de intrusos, como cobras e lagartos, ou contra o vento e a chuva, e para impedir o crescimento de fungos e bactérias. A colônia de uma abelha é capaz de coletar de 150 a $200 \mathrm{~g}$ de própolis em ano; no entanto, algumas colônias coletam menos que isso. Aristóteles cunhou a palavra própolis das palavras gregas pro (antes) e polis (cidade), ou seja, antes da cidade ou defensor da cidade (Martinotti \& Ranzato, 2015).

Pode-se dizer que a própolis vem sendo usada como medicamento no sistema medicinal tradicional desde os tempos antigos, devido às suas excelentes propriedades biológicos. O uso da própolis pelos seres humanos tem uma longa história anterior apenas à descoberta do mel. Alega-se que seja útil em cosméticos e prevenção contra hiperpigmentação. Os extratos de própolis foram relatados como tendo atributos biológicos consideráveis, como o anticâncer, antioxidante, antimicrobiano, anti-inflamatório, antiviral e efeitos hepatoprotetores (Pillai et al., 2010).

Pesquisadores identificaram mais de 300 compostos na própolis, a maioria destes compostos são formas de polifenóis, antioxidantes que combatem doenças e danos no organismo. Especificamente, a própolis contém os polifenóis chamados flavonóides. Os flavonóides são produzidos nas plantas como uma forma de proteção e são cinco comumente encontrados em alimentos com propriedades antioxidantes, incluindo: frutas; chá-verde; legumes e vinho tinto (Silva et al., 2019).

De acordo com Silva (2018), a própolis é uma resina dura, composta geralmente por aproximadamente $50 \%$ de resina e bálsamo, 30\% de cera, $10 \%$ de óleos essenciais e aromáticos, $5 \%$ de pólen e $5 \%$ de várias outras substâncias. A própolis é derivada de diferentes partes da planta, como brotos, botões de flores e exsudatos resinosos. Este trabalho tem por objetivo abordar o efeito cicatrizante e hepatoprotetor da própolis.

\section{Revisão e discussão}

Trata-se de um estudo de revisão de literatura narrativa. A abordagem do estudo é exploratório-descritiva: exploratório, pois intenciona desenvolver no pesquisador o conhecimento acerca do tema, por meio do processo de seleção e análise dos artigos científicos; descritiva, pois descreve as características dos artigos que compõem a bibliografia, em termos dos periódicos que mais publicaram sobre o tema, dos artigos com maior reconhecimento científico, dos autores de maior destaque e das palavras-chaves mais. Quanto à abordagem do problema, o trabalho pode ser enquadrado como qualitativo, que nos permite ir além dos dados quantitativos, e assim requer um olhar subjetivo para os sentidos e significados existentes em um contexto, produzidos por um determinado grupo (Rodrigues, 2007).

Pillai et al. (2010) em seu trabalho assegura que, a cicatrização de feridas, uma resposta fundamental à lesão tecidual, é um processo complexo que envolve mecanismos como coagulação, inflamação, síntese e deposição de matrizes, angiogênese, fibroplasia, epitelização, contração e remodelação. A progressão suave desses eventos leva à conclusão precoce do fechamento da ferida. O sucesso da cicatrização de feridas requer coordenação e sinalização precisa de várias células que produzem uma variedade de citocinas, fatores de crescimento, substâncias essenciais e colágenos.

O estudo de Martinotti \& Ranzato (2015) demonstrou que a aplicação de própolis aumenta a taxa de cicatrização de feridas e a reepitelização de feridas diabéticas em roedores. Também propôs outros papéis para a própolis na diminuição da infiltração de neutrófilos e na normalização do influxo de macrófagos na área ferida. O reparo e a regeneração de feridas ocorrem através de um padrão finamente ajustado de fases integradas, como hemostasia, inflamação, proliferação celular e remodelação de tecidos, que envolvem vários processos celulares e moleculares. Esse fenômeno inclui migração e proliferação de células e queratinócitos epidérmicos, adesão a fibroblastos e contração da matriz extracelular (MEC). O tratamento com própolis estimula aumentos significativos nos componentes da MEC durante a fase inicial do reparo da ferida seguida por uma redução nas moléculas da MEC. Postula-se que esse efeito biológico da própolis esteja associado à sua capacidade de estimular a expressão do fator de crescimento transformador- $\beta$ (TGF $\beta$ ) que participa das fases iniciais do reparo de feridas, como hemostasia e inflamação.

McLennan et al. (2008) em pesquisa mostrara que, com uma única própolis tópica, há um aumento da cicatrização de feridas em um modelo de roedor diabético de cicatrização cutânea de espessura total. Este foi o primeiro estudo sistemático mostrando que a própolis melhora a cicatrização de feridas no diabetes. Estudos demonstraram ainda que própolis é capaz de realizar um bom processo de cicatrização principalmente pela redução da resposta inflamatória; então, o processo de cicatrização foi mais rápido com a própolis. Os autores consideraram a própolis adequada para o tratamento de feridas, após a erradicação da infecção. 
De acordo com Martinotti \& Ranzato (2015). As propriedades curativas da própolis devem ser também devidas ao seu efeito estimulante imunológico. Essa propriedade foi caracterizada em poucos estudos clínicos. A própolis foi administrada e a capacidade de secreção de citocinas foi considerada durante e após o tratamento. A capacidade de secreção de citocinas aumentou significativamente durante o período de tratamento de maneira dependente do tempo. Os autores concluíram que a própolis foi capaz de desencadear uma reatividade imunológica sem efeitos colaterais

Para Silva et al. (2019) sobre o uso da própolis como hepatoprotetor afirmam que, como o fígado é o principal órgão do metabolismo de compostos, muitas doenças hepáticas aparecem por sua exposição a substâncias tóxicas, e o estresse oxidativo promovido por essas substâncias é muito importante nos mecanismos fisiopatológicos dessas doenças. Como a própolis possui substâncias bioativas com potencial antioxidante, anti-inflamatório e geno protetor, o extrato etanólico da própolis vermelha pode prevenir ou minimizar os danos às células hepáticas quando expostos a substâncias hepatotóxicas.

De acordo com Amelia et al. (2016), a reação de estresse oxidativo pode causar lesão hepática. Este processo pode ser evitado por atividades antioxidantes que podem quebrar a cadeia destrutiva causada por substâncias dos radicais livres no fígado. Própolis produzida por Trigona spp. Abelha é conhecida por ter um alto nível de antioxidante

No estudo de Silva et al. (2019), o extrato de própolis promoveu efeito geno protetor, reduzindo os danos no DNA das células hepáticas danificadas pelo H2O2, além de não exercer efeito citotóxico nas células normais (L929), demonstrando atividade anti-neoplásica na linha celular do carcinoma hepatocelular humano (HepG2), em qual a própolis vermelha é um candidato promissor para inibir o crescimento celular e contribuir para as diferentes etapas relacionadas ao processo de carcinogênese.

Ambardekar et al. (2012) ressalta ainda que a eficácia hepatoprotetora da própolis é limitada por sua baixa absorção oral. Além disso, a composição exata da própolis sendo ainda indefinida. Para resolver o problema anteriormente citado, lipossomas de própolis adequados para administração oral e com maior eficiência de aprisionamento foram formulados através de um método de injeção de etanol modificado. A formulação foi capaz de suprimir os níveis de AST, ALT, ALP e TBARS em animais experimentais induzidos por hepatotoxicidade e promover a cicatrização dos tecidos, de uma maneira mais eficaz.

\section{Considerações finais}

A própolis apresenta em sua composição polifenóis que resultam em um efeito antioxidante, além disso, a própolis também contém compostos ativos que são conhecidos por promover a proliferação ou apoptose celular. Em relação ao seu emprego como cicatrizante demonstrou que a aplicação de própolis aumenta a taxa de cicatrização de feridas pela redução da resposta inflamatória. Ao que tange a utilização da própolis como hepatoprotetor, o seu extrato promoveu efeito geno protetor, reduzindo os danos no DNA das células hepáticas danificadas, mas por ser administrada pela via oral, a eficácia hepatoprotetora da própolis é limitada.

\section{Referências}

Ambardekar, R. V., Mahadik, K. R., Paradkar, A. R., \& Harsulkar, A. M. 2012. Enhancement of hepatoprotective efficacy of propolis by fabrication of liposomes, as a platform nano-formulation for multi-component natural medicine. Current Drug Delivery, 9(5), 477-486.

Amelia, R., Achadiyani, A., \& Bestari, M. B. 2016. Hepatoprotective Effect of Trigona spp. Bee Propolis against Carbon Tetrachloride-Induced Liver Injury in Rat. Althea Medical Journal, 3(3), 482-486.

Martinotti, S., \& Ranzato, E. 2015. Propolis: a new frontier for wound healing? Burns \& Trauma, 3(9), 1-10.

McLennan, S. V., Bonner, J., Milne, S., Lo, L., Charlton, A., Kurup, S., Jia, J., Yue, D. K., \& Twigg, S. M. 2008. The anti-inflammatory agent Propolis improves wound healing in a rodent model of experimental diabetes. Wound Repair and Regeneration, 16(5), 706-713.

Oryan, A., Alemzadeh, E., \& Moshiri, A. 2018. Potential role of propolis in wound healing: biological properties and therapeutic activities. Biomedicine \& Pharmacotherapy, 98, 469-483,

Pillai, S. I., Palsamy, P., Subramanian, S., \& Kandaswamy, M. 2010. Wound healing properties of Indian propolis studied on excision wound-induced rats. Pharmaceutical Biology, 48(11), 1198-1206.

Rodrigues, W. C. 2007. Metodologia Científica. 1-20. 
Silva, J. B., Paiva, K. A. R., Costa, K. M. F. M., Viana, G. A., Araújo Júnior, H. N., Bezerra, L. S., Freitas, C. I. A., \& Batista, J. S. 2019. Hepatoprotective and antineoplastic potencial of red propolis produced by the bees Apis mellifera in the semiarid of Rio Grande do Norte, Brazil. Pesquisa Veterinária Brasileira, 39(9), 744756.

SILVA, Karla Camyla Morais da et al. Os diferentes tipos de própolis e suas indicações: uma revisão da literatura. 2018.

\section{Minicurrículo}

Luiz Henrique Hoffmann. Graduando no curso de Farmácia da Faculdade Fapal. Palmas, Tocantins (TO), Brasil.

Maykon Jhuly Martins de Paiva. Graduação em Farmácia Generalista pelo Centro Universitário Tocantinense Presidente Antônio Carlos. (UNITPAC), aperfeiçoamento em saúde pública. Especialização Lato Sensu em Biotecnologia pela Universidade Católica Dom Bosco (UCDB). Especialização Lato Sensu em Farmácia Clinica e Hospitalar pela Faculdade Dom Alberto (FDA). Mestrado pelo programa de Pós-Graduação em ciência e tecnologia de alimentos da Universidade Federal do Tocantins. Atualmente é docente do curso de farmácia e estética e cosmetologia da Faculdade de Palmas (FAPAL) e Presidente do Conselho Regional de Farmácia do Tocantins. Atualmente trabalha como temas relacionados à Farmácia, Farmacologia, Biotecnologia, Microbiologia, Ciência e Tecnologia de Alimentos e Saúde Pública.

Como citar: Hoffmann, L.H., \& Paiva, M.J.M 2021. O uso da própolis como agente cicatrizante e hepatoprotetor. Pubsaúde, 6, a189. DOI: https://dx.doi.org/10.31533/pubsaude6.a189

Recebido: 17 mai. 2021.

Revisado e aceito: 4 jun. 2021.

Conflito de interesse: os autores declaram, em relação aos produtos e companhias descritos nesse artigo, não ter interesses associativos, comerciais, de propriedade ou financeiros que representem conflito de interesse.

Licenciamento: Este artigo é publicado na modalidade Acesso Aberto sob a licença Creative Commons Atribuição 4.0 (CC-BY 4.0). 